\title{
Tired, weak, or in need of rest: fatigue among general practice attenders
}

\author{
Anthony David, Anthony Pelosi, Elizabeth McDonald, David Stephens, David Ledger, \\ Richard Rathbone, Anthony Mann
}

\begin{abstract}
Objectives-To determine the prevalence and associations of symptoms of fatigue.

Design-Questionnaire survey.

Setting-London general practice.

Participants-611 General practice attenders.

Main outcome measures-Scores on a fatigue questionnaire and reasons given for fatigue.

Results $-10 \cdot 2 \%$ Of men $(17 / 167)$ and $10 \cdot 6 \%$ of women (47/444) had substantial fatigue for one month or more. Age, occupation, and marital status exerted minor effects. Subjects attributed fatigue equally to physical and non-physical causes. Physical ill health, including viral infection, was associated with more severe fatigue. Women rather than men blamed family responsibilities for their fatigue. The profile of persistent fatigue did not differ from that of short duration. Only one person met criteria for the chronic fatigue syndrome.

Conclusions-Fatigue is a common complaint among general practice attenders and can be severe. Patients may attribute this to physical, psychological, and social stress.
\end{abstract}

\section{Introduction}

Fatigue is a common, perhaps universal complaint. In a recent British survey about $20 \%$ of men and $30 \%$ of women admitted to "always feeling tired" during the previous week,' and similar data have been reported from the United States. ${ }^{2}$ Fatigue is also common among people attending their doctors, though the reported prevalence depends on the way the question is asked. One large study on general practice showed that $23 \%$ of women and $13 \%$ of men answered positively the question, "Do you often get spells of complete exhaustion or fatigue?" Similarly, an investigation into fatigue in a United States army primary medical care centre found that $28 \%$ of female and $19 \%$ of male attenders indicated that this had been a "major problem" for a month or more.

In both primary care and community studies higher rates of fatigue have often been found in women, ${ }^{1-6}$ though age does not seem to have a consistent association with fatigue, ${ }^{5}$ except perhaps an inverse association in women.${ }^{17}$ Data from this last survey also showed a modest increase in the prevalence of fatigue among those with semiskilled and unskilled manual occupations.

Fatigue is a non-specific symptom; it occurs in most physical illnesses ${ }^{8}$ and many psychiatric disorders. ${ }^{9.13}$ It has recently caught the public and professional imagination with the emergence of a possibly specific chronic fatigue syndrome, perhaps of postinfectious origin. ${ }^{14}{ }^{15}$ Anecdotally it is said to occur in early adult life, to occur after acute infection, to have a female preponderance, and to occur particularly in those of high occupational status, especially medical and paramedical professionals. ${ }^{14} 16-18$ As a group, subjects with chronic fatigue syndromes are said to make physical attributions about ill health. ${ }^{713}$ Some or all of these associations could be explained on the basis of a selection bias which results in a subgroup of sufferers who are investigated in hospital based studies. ${ }^{14}$

To date there has been no study in primary care in the United Kingdom which has specifically investigated the various components of fatigue. We therefore conducted a questionnaire survey about fatigue among adults attending a south London group general practice between November 1989 and January 1990. The aims were: $(a)$ to estimate the prevalence of the various symptoms of fatigue in a primary care population using a specially developed questionnaire; $(b)$ to examine the associations with fatigue discussed above; and $(c)$ to explore patients' own explanations for this symptom.

\section{Methods}

Six group practices in south east London were approached to participate in the study. Although all expressed interest, only one took part. (The others stated that time for research had been taken up by the dramatic rise in administration due to the proposed changes in the NHS.) This was a three doctor practice in Herne Hill serving a population of around 9000 . Because of the proximity of the King's College Hospital group an above average number of medical, paramedical, and nursing professionals were registered with the practice. Questionnaires, which also outlined the purposes of the study, were distributed by a research assistant to all adults over 18 as they entered the waiting room.

Assessments consisted of sociodemographic details and a fatigue questionnaire. Occupational grouping followed the method of Goldthorpe and Hope, ${ }^{19}$ but wives were allocated to social class by their own rather than their husbands' occupation.

The fatigue questionnaire was based on that used in a previous hospital study of chronic fatigue. ${ }^{7}$ The questions were: Do you get tired easily? Do you need rest? Do you feel sleepy or drowsy? Do you find it difficult to start doing things? Do you start things easily but get weak as you go on? Do you get tired when you have to concentrate? Do you have enough energy? Do you have enough strength in your muscles? Do you feel weak? A tenth question asked how often subjects felt tired during the day. If tiredness or fatigue had been present, its duration was determined. Lastly, two lines were provided for each patient to say, if applicable, why he or she had been "feeling tired."

During pilot studies each symptom was measured with a four point Likert scale as used in the general health questionnaire. ${ }^{20}$ It became clear that some of 
those with chronic fatigue, who indicated that their symptoms were "the same as usual," were being misidentified. We therefore modified the questionnaire to ask whether subjects had experienced the symptom in the previous two weeks and, if so, whether it had been the same, more, or much more than usual. Results reported here are from the revised questionnaire. A total fatigue score was obtained for each subject: a score of 1 was given if a symptom had been present and was "the same as usual," 2 for more than usual," and 3 for "much more than usual." Individual item scores for the first nine questions were summed, yielding a maximum possible 27 . We defined subjects as suffering from chronic fatigue if they scored greater than or equal to 9 on the fatigue questionnaire and gave a duration of greater than three months.

\section{Results and comment}

Four hundred and forty four women and 167 men completed the revised assessment. Thirty five declined to participate. The mean age was 38.8 years $(95 \%$ confidence interval 36.5 to $41 \cdot 1$ ) for men and 33.2 years (32 to $34 \cdot 5$ ) for women. Of 163 men who supplied details, 88 were married or cohabiting, 61 were single, and 14 were divorced, separated, or widowed. Of the 437 women who gave their marital status 210 were married or cohabiting, 197 were single, and 30 were divorced, separated, or widowed. The excess of single unmarried women reflected the population served by the practice.

In social class I there were 41 men and 17 women; social class II 50 men and 151 women; social class III nine men and 83 women; social classes IV-VI 35 men and 14 women. There were 12 male and 67 female students (mostly nurses), 10 men and 14 women were retired, and only four men stated that they were unemployed. Seventy eight of the women were "housewives," thus the composition of our sample was predominantly middle class.

\section{TOTAL FATIGUE SCORES}

The median fatigue score was 4 (figure).

Sex differences-Mean total fatigue scores were $5 \cdot 2$ $(4 \cdot 4$ to 6$)$, median 3 , for the men and $6 \cdot 0(5 \cdot 5$ to $6 \cdot 6)$, median 4 , for the women $(t=1 \cdot 52 ; \mathrm{p}=0 \cdot 13$, NS). In view of the skewed distribution of scores the effect of sex was also analysed non-parametrically and by logarithmic transformation of total scores. The MannWhitney $U$ test was also not significant $(p=0 \cdot 14)$; nor was the $t$ test using transformed data $(p=0.096)$ though the trend was towards higher scores in women. Total score correlated with frequency $(r=0.49 ; p<0.001)$ and weakly with duration $(\mathrm{r}=0 \cdot 18 ; \mathrm{p}<0.01)$. An analysis that ranked duration showed, as expected,

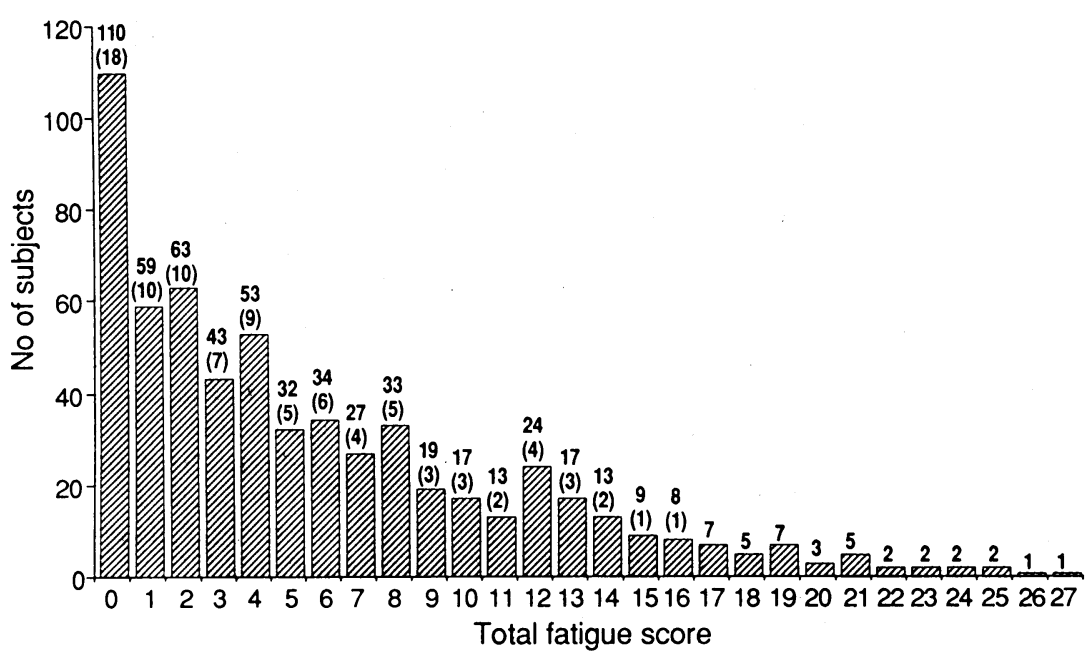

Frequency distribution of total fatigue scores. Values are numbers (and percentages).
TABLE I-Prevalence of individual symptoms of fatigue for men and women

\begin{tabular}{|c|c|c|c|c|}
\hline Symptom & None & $\begin{array}{c}\text { Same as } \\
\text { usual }\end{array}$ & $\begin{array}{c}\text { More than } \\
\text { usual }\end{array}$ & $\begin{array}{l}\text { Much more } \\
\text { than usual }\end{array}$ \\
\hline \multicolumn{5}{|c|}{ Tired easily ${ }^{\star \star}$} \\
\hline Men & $101(60)$ & $33(20)$ & $22(13)$ & $11(7)$ \\
\hline Women & $204(46)$ & $91(21)$ & $116(26)$ & $33(7)$ \\
\hline \multicolumn{5}{|l|}{ Need rest ${ }^{\star}$} \\
\hline Men & $74(44)$ & $61(37)$ & $26(16)$ & $6(4)$ \\
\hline Women & $172(39)$ & $130(29)$ & $118(27)$ & $23(5)$ \\
\hline \multicolumn{5}{|l|}{ Feel sleepy } \\
\hline Men & $89(53)$ & $41(25)$ & $32(19)$ & $5(3)$ \\
\hline Women & $242(55)$ & $92(21)$ & $97(22)$ & $13(3)$ \\
\hline \multicolumn{5}{|c|}{ Difficult starting } \\
\hline Men & $107(64)$ & $21(13)$ & $34(20)$ & $4(3)$ \\
\hline Women & $305(69)$ & $49(11)$ & $74(17)$ & $16(4)$ \\
\hline \multicolumn{5}{|c|}{ Tired after starting } \\
\hline Men & $122(73)$ & $17(10)$ & $25(15)$ & $3(2)$ \\
\hline Women & $322(72)$ & $53(12)$ & $58(13)$ & $11(3)$ \\
\hline \multicolumn{5}{|c|}{ Concentration } \\
\hline Men & $112(68)$ & $30(18)$ & $22(13)$ & $2(2)$ \\
\hline Women & $265(60)$ & $104(23)$ & $65(15)$ & $8(2)$ \\
\hline \multicolumn{5}{|l|}{ Energy } \\
\hline Men & $97(58)$ & $27(16)$ & $38(23)$ & $5(3)$ \\
\hline Women & $226(51)$ & $60(14)$ & $130(29)$ & $28(6)$ \\
\hline \multicolumn{5}{|l|}{ Strength } \\
\hline Men & $129(77)$ & $16(10)$ & $17(10)$ & $5(3)$ \\
\hline Women & $346(78)$ & $36(8)$ & $51(11)$ & $11(3)$ \\
\hline \multicolumn{5}{|l|}{ Feel weak } \\
\hline Men & $127(76)$ & $12(7)$ & $23(14)$ & $4(2)$ \\
\hline Women & $329(74)$ & $35(8)$ & $64(14)$ & $15(4)$ \\
\hline
\end{tabular}

Significant sex difference: ${ }^{\star} \mathrm{p}<0.02,{ }^{\star \star} \mathrm{p}<0.005$.

TABLE II - Frequency of fatigue in 589 men and women who answered this question. Results are numbers and percentages

\begin{tabular}{lcccc}
\hline Frequency & Never & Sometimes & $\begin{array}{c}\text { Most of the } \\
\text { day }\end{array}$ & $\begin{array}{c}\text { All the } \\
\text { time }\end{array}$ \\
\hline $\begin{array}{l}\text { Men } \\
\text { Women }\end{array}$ & $10(6)$ & $132(82)$ & $18(11)$ & $2(1)$ \\
\hline
\end{tabular}

that those with the briefest duration of fatigue symptoms had the lowest total scores.

Age-There was no correlation between age and the total fatigue score for men or women (overall $\mathrm{r}=0.057$ ). The only item with which age correlated significantly was duration $(r=0.28 ; p<0.001)$. Analysis of variance comparing total fatigue scores by sex with age as covariate showed no main effect for $\operatorname{sex}(F=1 \cdot 46$; $\mathrm{p}=0.23)$ or age $(\mathrm{F}=1.5 ; \mathrm{p}=0 \cdot 21)$. There was no significant interaction between sex and age when subjects were classified as either above or below 45 years $(\mathrm{F}=0 \cdot 068 ; \mathrm{p}=0 \cdot 8)$.

Marital status was not associated with differences in total fatigue score. There was a slight trend in both men and women towards higher scores for those who were divorced, separated, or widowed than for those who were married, cohabiting, or single, but differences were small and not statistically significant.

Occupation-No differences emerged in the level of fatigue according to occupational group in either sex. Classifying women according to their husband's occupation did not alter these findings. When medical, nursing, and paramedical workers $(n=129)$ were compared with other subjects in social classes I and II there were no differences in mean fatigue scores $(p=0 \cdot 26$, NS; Mann-Whitney U test, 2 tailed).

\section{RESPONSES TO INDIVIDUAL ITEMS}

Sex differences-Individual symptoms of fatigue plus their frequency and duration are outlined in tables I-III for men and women separately. The responses of men and women were similar except for small but statistically significant differences for two items: women complained of tiring more easily $\left(\chi^{2}=14 \cdot 3\right.$; $\mathrm{df}=3, \mathrm{p}<0.005)$ and needing more rest $\left(\chi^{2}=9.8 ; \mathrm{df}=3\right.$, $\mathrm{p}<0.02)$. Women also tended to score more highly in the question on lack of energy $\left(\chi^{2}=6 \cdot 1 ; \mathrm{df}=3\right.$, $\mathrm{p}=0 \cdot 11)$. Responses to the questions on duration and frequency of fatigue showed no statistically significant sex differences, although in total $86(14 \%)$ complained 
TABLE III - Duration of symptoms of fatigue in 439 men and women who answered this question. Results are numbers and percentages

\begin{tabular}{lcccccr}
\hline Duration & $\begin{array}{c}<1 \\
\text { Week }\end{array}$ & $\begin{array}{c}1-2 \\
\text { Weeks }\end{array}$ & $\begin{array}{c}3-4 \\
\text { Weeks }\end{array}$ & $\begin{array}{c}1-2 \\
\text { Months }\end{array}$ & $\begin{array}{c}3-6 \\
\text { Months }\end{array}$ & $\begin{array}{c}>6 \\
\text { Months }\end{array}$ \\
\hline Men & $26(23)$ & $20(18)$ & $12(11)$ & $13(12)$ & $9(8)$ & $33(29)$ \\
Women & $58(18)$ & $48(15)$ & $30(9)$ & $50(15)$ & $36(11)$ & $104(32)$ \\
\hline
\end{tabular}

of feeling tired most or all of the time, and only $11(2 \%$; 2 men, 9 women) said that they felt tired "all the time.'

Factor analysis-All of the items in the fatigue questionnaire, except for those on duration, were positively intercorrelated $(0 \cdot 21<\mathrm{r}<0 \cdot 65)$. Principal components analysis yielded a single factor solution with the first factor accounting for $48.6 \%$ of the variance and the other items descending in linear order from $9 \cdot 7 \%$ to $3 \cdot 1 \%$. The factor loading ranged from 0.58 for poor concentration to 0.79 for tiring easily. Though this supports the notion that a single construct, "fatigue," is being measured, different items did elicit a wide range of responses. For example, the number of subjects scoring less or much less than usual ranged between 14\% (84/611) and 33\% (201/611) for the questions, Do you have enough strength in your muscles? and Do you have enough energy? respectively. Furthermore, questions which might have elicited a separate mental fatigue factor, as in the hospital study, which used a longer questionnaire, ${ }^{12}$ were limited to one question about concentration.

Chronic fatigue-Seventy people $(11.5 \%$ of the sample) were suffering from "chronic fatigue" as defined earlier. Fifty five were women $(12 \%$ of all women), mean age 38 years, and 15 men ( $9 \%$ of all men), mean age 41 ; the proportions of each gender did not differ significantly from the group as a whole. The validity of our cut off point was checked against the results of a standardised assessment using the revised clinical interview schedule (available on request from Dr G Lewis, Institute of Psychiatry) administered between 1 and 3 months after the questionnaire. Of the 70 people 65 were interviewed: 60 of these scored 2 or more and 523 or more on the section concerning fatigue, where 1 indicates mild and 4 indicates severe symptoms. A random sample of 29 patients taken from those who scored below 9 on the questionnaire but who had had symptoms for at least six months were contacted. A brief assessment over the telephone was made on 25 people, which confirmed that only seven considered their fatigue to be a major problem. Therefore the 9 point cut off adopted to select relatively

TABLE IV-Patients' reasons for fatigue

\begin{tabular}{lrr}
\hline Reasons given for fatigue & $\begin{array}{c}\text { Men } \\
(\mathrm{n}=110)\end{array}$ & $\begin{array}{r}\text { Women } \\
(\mathrm{n}=314)\end{array}$ \\
\hline Physical reasons & $60(55)$ & $147(47)$ \\
Social & $28(25)$ & $72(23)$ \\
Emotional & $18(16)$ & $39(12)$ \\
Family & $3(3)$ & $56(18)$ \\
Lack of sleep & $16(15)$ & $48(15)$ \\
Viral infection & $3(3)$ & $3(1)$ \\
Myalgic encephalomyelitis/postviral fatigue & & \\
$\quad$ syndrome & $1(1)$ & $2(1)$ \\
Other & $7(6)$ & $35(11)$ \\
Pregnancy & - & $19(6)$ \\
\hline
\end{tabular}

The column totals exceed $100 \%$ since a few subjects gave two reasons for their fatigue and a few gave three reasons.

TABLE $\mathrm{V}-$ Reasons for fatigue and mean total fatigue score

\begin{tabular}{lc}
\hline Reason for fatigue & $\begin{array}{c}\text { Mean fatigue score } \\
\text { (95\% confidence interval) }\end{array}$ \\
\hline $\begin{array}{lc}\text { Not due to physical ill health }(\mathrm{n}=323)^{\star} \\
\begin{array}{l}\text { Mye to physical ill health }(\mathrm{n}=105) \\
\text { infection }(\mathrm{n}=6)\end{array}\end{array}$ & $\begin{array}{c}5 \cdot 9(5 \cdot 4 \text { to } 6 \cdot 4) \\
10 \cdot 8(9 \cdot 6 \text { to } 12 \cdot 1)\end{array}$ \\
\hline
\end{tabular}

^Differs significantly from other two groups at 0.05 level (Scheffé procedure). severe and chronic cases appeared to have reasonable sensitivity and specificity. When the chronic group was compared with the rest of the patients there were no major differences in occupation, except that housewives (19/78) and women whose occupations were coded as social classes IV-VI (3/14) tended to have chronic fatigue more often. Divorced, separated, or widowed women were overrepresented $(9 / 30)$, while single women were slightly underrepresented (17/197) $\left(\chi^{2}=11 \cdot 3, \quad \mathrm{df}=2 ; \mathrm{p}<0.005\right)$. We also compared individual items relating to fatigue in those with symptoms for longer than three months and those with symptoms for one month or less. The profile in the two groups was essentially the same.

\section{REASONS GIVEN FOR FATIGUE}

One hundred and ten men and 314 women filled out the part of the questionnaire that asked them to explain why they believed they were feeling tired. We categorised their responses as: physical ill health (diabetes, anaemia, recent operation, flu, virus, etc), social factors (often employment related such as night shift work or overwork), emotional problems (depression, stress, tension, etc), or family reasons (such as looking after young children or marital stress). Also categorised separately were lack of sleep and pregnancy. A miscellaneous category contained a variety of causes of fatigue including: old age (12), lack of fresh air (3), diet (8). Myalgic encephalomyelitis, postviral fatigue, and prolonged viral infection were analysed as separate causes. When more than one explanation was given all were recorded, and all explanations are included in table IV. When there was more than one reason viral infection took precedence in categorising the patient, followed by physical causes, followed by any other causes.

There were pronounced differences in fatigue severity depending on patients' views about the cause. Those who blamed physical ill health had higher total fatigue scores than those with either family, social, or emotional reasons or poor sleep. The small number blaming past or present infection with a virus scored highest of all (see table V). When the same three groups were compared for duration of fatigue no significant differences emerged, though those who blamed physical problems tended to have had fatigue for a shorter time. Several women blamed pregnancy (16; mean score $5.8(4 \cdot 2$ to $7 \cdot 5))$ or the need to care for young children ( 37 ; score $10 \cdot 4(7 \cdot 5$ to $13 \cdot 4)$ ), or both (3; score $18 \cdot 7(10 \cdot 7$ to $26 \cdot 7)$ ), for their tiredness.

We identified six patients (three men, three women) who attributed their fatigue to myalgic encephalomyelitis or persistent viral illness. Only one (a man) could be considered to have a chronic fatigue syndrome (significant fatigue of duration greater than six months $)^{21}$ of presumed postviral origin. Of the remainder, one said she had fully recovered and the other four had had either moderate or severe fatigue for less than six months. A seventh subject declined to fill in the questionnaire, indicating that she had "ME."

\section{Conclusions}

This general practice questionnaire survey of 611 adults in a predominantly middle class suburb of south east London has confirmed findings in previous studies $^{4-6}$ that symptoms of fatigue are common among those attending their doctor. However, our present investigation was limited to only one London practice so the population cannot be claimed to be wholly representative. Furthermore, precise comparison with other data is not possible because of the variations in the way fatigue symptoms were elicited. Nevertheless, $10.2 \%$ of men and $10.6 \%$ of women complained of feeling tired all or most of the time for more than a 
month, somewhat lower figures than those obtained in a United States primary care study.

Men and women differed in their responses to certain questions from the fatigue questionnaire, though when fatigue scores were summed important associations with gender failed to emerge. There was, however, one striking gender difference which has important practical implications: several women but very few men complained of fatigue due to family reasons, including caring for young children. Moreover, since more women than men attend their general practitioners a community survey probably would show more fatigued women than men. There was no evidence for the influence of age on total fatigue score, though there was a weakly positive correlation between age and duration.

There were only minor differences in the various occupational groups, including medical and paramedical professions, and in those of different marital status. Working class housewives with young children and without their partners seemed more likely to suffer from fatigue; similar results have been shown in studies of depression. ${ }^{22}$

The patients' reasons for fatigue were wide and varied, with subjects equally liable to point to a social or emotional cause as to a physical one. When these reasons were related to the symptom levels, however the more severely affected tended to attribute the symptom to physical ill health, including viral and postviral causes. It is not possible to say whether fatigue from these physical causes is more severe per se or whether more severe fatigue leads people to make physical attributions. We thought that asking attenders for a precise description of their illness on the questionnaire would be intrusive so we cannot assess the plausibility or accuracy of each attribution. Similarly, the important relation between symptoms of fatigue and psychiatric disorder ${ }^{9-13}$ was not examined in his study. A further detailed physical and psychological assessment is currently under way which will clarify these issues.

Those with prolonged tiredness did not show noticable qualitative differences in the pattern of their symptoms from those whose fatigue was brief. For example, pronounced fatigability and muscle weakness were not more prominent. This finding can be interpreted in two ways. It suggests either that the chronic fatigue syndrome is a separate condition, discontinuous with fatigue in general, but was not in evidence in our sample, or that the stereotype of those with chronic fatigue syndrome, including their supposed sociodemographic characteristics, is an artefact of selection bias. Further work is needed to address this question. Despite the recent interest in a chronic fatigue syndrome shown in the medical and lay press, only six patients attributed their fatigue to a viral aetiology or myalgic encephalomyelitis and only one of these patients had severe and chronic fatigue. This observation is important as it counters the inflated claims of the frequency with which the syndrome occurs $^{2324}$ and is in keeping with the findings of a recent American primary care study. ${ }^{25}$

Clearly symptoms of fatigue, be they tiredness, weakness, poor concentration, or the subjective need for rest, are widespread among general practice attenders of all ages and both sexes. These symptoms are in themselves an important cause of morbidity and may be the manifestation of underlying physical, psychological, and social distress. General practitioners are particularly well placed to identify and help tackle these problems; and a primary care perspective has much to contribute to research into the nature, causes, and consequences of fatigue.

We thank all those at the Herne Hill practice who helped carry out the study and Brenda Robinson for her administrative help. Drs Glyn Lewis and Simon Wessely kindly gave us access to unpublished work. The project was supported by the Medical Research Council.

1 Cox B, Blaxter M, Buckle A, et al. The health and lifestyles survey. London: Health Promotion Research Trust, 1987.

2 Hammond E. Some preliminary findings on physical complaints from a prospective survey of 1,064,004 men and women. Am f Public Health 1964;54:11-23.

3 Chen MK. The epidemiology of self-perceived fatigue among adults. Prev Med 1986;15:74-81.

4 Shepherd M, Cooper B, Brown A, Kalton G. Psychiatric illness in general practice. 2nd ed. Oxford: Oxford University Press, 1981.

5 Kroenke K, Wood DR, Mangelsdorff AD, Meier NJ, Powell JB. Chronic fatigue in primary care: prevalence, patient characteristics and outcome. JAMA 1988:260:929-34.

6 Ingham JG, Miller PMcC. Symptom prevalence and severity in a general practice population. F Epidemiol Community Health 1979;33:191-8.

7 Wessely S. The epidemiology of fatigue: evidence from a UK community sample. MSc thesis. London School of Hygiene and Tropical Medicine, 1989

8 Harvard C. Lassitude. BMf 1985;290:1161-2.

9 Taerk GS, Toner BB, Salit IE, Garfinkel PE, Ozersky S. Depression in patients with neuromyasthenia (benign myalgic encephalomyelitis). Int F Psychiatry Med 1987;17:49-56.

10 Manu P, Matthews D, Lane T. The mental health of patients with a chief complaint of chronic fatigue: a prospective evaluation and follow-up. Ann Intern Med 1988:148:2213-7.

11 Kruesi MJP, Dale J, Straus SE. Psychiatric diagnoses in patients who have chronic fatigue syndrome. I Clin Psychiatry 1989;50:53-6.

12 Wessely S, Powell R. Fatigue syndromes: a comparison of chronic "postviral" fatigue with neuromuscular and affective disorders. $f$ Neurol Neurosurg Psychiatry 1989:52:940-8.

13 Hickie I, Lloyd A, Wakefield D, Parker G. The psychiatric status of patient Hickie I, Lloyd A, Wakefield D, Parker G. The psychiatric status of pate
with the chronic fatigue syndrome. $B r f$ Psychiatry 1990;156:534-40.

14 David AS, Wessely S, Pelosi AJ. Postviral fatigue syndrome: time for a new approach. BMF 1988;296:696-9.

15 Holmes G, Kaplan J, Gantz N, et al. Chronic fatigue syndrome: a working case definition. Ann Intern Med 1988;108:387-9.

16 Behan PO, Behan WMH, Bell EJ. The postviral fatigue syndrome-an analysis of findings in 50 cases. $\mathcal{F}$ Infect 1985;10:211-22.

17 Ramsay AM. Postviral fatigue syndrome: the saga of Royal Free disease. London: Gower Medical Publishing, 1986.

18 Dowsett EG, Ramsay AM, McCartney RA, Bell EJ. Myalgic encephalomyeltis - a persistent enteroviral infection? Postgrad Med f 1990;66:526-30.

19 Goldthorpe J, Hope K. The social grading of occupations: a new approach and scale. Oxford: Oxford University Press, 1974.

20 Goldberg DG, Williams P. A manual of the general health questionnaire. Oxford: Oxford University Press, 1988.

21 Dawson J. Consensus on research into fatigue syndrome. BMf 1990;300:832. 22 Brown GW, Harris T. The social origins of depression. London: Tavistock, 978.

23 Calder BD, Warnock PJ, McCartney RA, Bell EJ. Coxsackie B viruses and the post-viral syndrome: a prospective study in general practice. $f R$ Coll Gen Pract 1987;37:11-4.

24 Smith D. Understanding $M E$. London: Robinson, 1989.

25 Manu P, Lane TJ, Matthews DA. The frequency of the chronic fatigue syndrome in patients with symptoms of persistent fatigue. Ann Intern Med 1988;159:554-6.

(Accepted 31 August 1990) 